\title{
A pesquisa de Educação Ambiental em encontros regionais ${ }^{1}$
}

\author{
Ademir José Rosso ${ }^{2}$, Adriana Ribeiro Ferreira ${ }^{3}$, Franciely \\ Ribeiro dos Santos ${ }^{4}$, Bernadete Machado e Fernando Zan Vieira ${ }^{6}$
}

Resumo: O artigo analisa o VII Encontro de Educação Ambiental do Estado do Rio de Janeiro (VII EEA-RJ, 2003) e o IX Encontro Paranaense de Educação Ambiental (IX EPEA-PR, 2006). Problematiza a origem dos trabalhos, a natureza dos textos e os seus objetivos frente à intencionalidade de pesquisa em Educação Ambiental (EA). Foram documentados 139 trabalhos completos, disponibilizados por meio eletrônico ou CD-ROM. Da leitura e fichamento, coletaram-se informações sobre a indexação dos textos, palavras-chave, problemas de pesquisa, objetivos, hipótese(s), metodologias, populações investigadas, resultados, conclusões, questões em aberto e referências. O processamento das informações mediante a análise de conteúdos formou três categorias textuais e seis de objetivos. Dos 139 trabalhos, 56 foram classificados na categoria de pesquisa, e desses, 33 apresentaram objetivos dessa categoria. As informações analisadas manifestam: a diversidade de padrões textuais, das relações entre elementos teóricos e empíricos, do planejamento e relatório das investigações, bem como a produção de uma comunidade científica em formação e diferentes graus de envolvimento na pesquisa.

Palavras-chave: Educação Ambiental. Pesquisa. Trabalhos em Eventos.

1 Versão parcial apresentada no IV Encontro de Pesquisa em Educação Ambiental, 2007, Rio Claro.

2 Licenciado em Ciências e Biologia. Doutor em Educação pela Universidade Federal de Santa Catarina. Professor da Licenciatura em Biologia e do Programa de PósGraduação em Educação da Universidade Estadual de Ponta Grossa. Contatos: R. Henrique Thielen, 61 - Jd. Carvalho - Ponta Grossa - PR CEP 84.015-650 ou ajrosso@uepg.br

3 Licenciada em Biologia. Mestre em Educação pela Universidade Estadual de Ponta Grossa. adrirf@pop.com.br

4 Licenciada em Geografia. Mestre em Educação pela Universidade Estadual de Ponta Grossa. franciely_rs_15@yahoo.com.br

5 Licenciada em Pedagogia. Mestre em Educação pela Universidade Estadual de Ponta Grossa. machado_be@yahoo.com.br

6 Bacharel em Direito e Licenciado em História. Mestrando do Programa de PósGraduação em Educação da Universidade Estadual de Ponta Grossa. vonstolzing@yahoo.com.br 
Abstract: This article analyses the VII Environmental Education Meeting of the State of Rio de Janeiro (VII EEA-RJ, 2003) and the IX Environmental Education Meeting of the State of Paraná (IX EPEA-PR, 2006). The analysis was carried out considering the origin of the works, the nature of the texts and their objectives regarding the research on Environmental Education (EE). All the 139 works documented are available in electronic format or on CD-ROM. By reading and outlining the texts it was possible to collect information on their indexings, keywords, research questions, objectives, hypothesi(e)s, methodologies, communities investigated, results, conclusions, still open issues, and references. The data processing through content analysis brought up three textual categories and six categories related to objectives. 56 works out of 139 were classified as researches, and 33 out of these presented related objectives. The information analysed shows diversity of textual patterns, of the relations between theoretical and empirical elements, and of the ways by which the investigations were planned and reported. In addition, it shows the production of a developing scientific community and different levels of research involvement.

Keywords: Environmental Education. Research. Works in Events.

\section{Introdução}

O debate sobre as produções de Educação Ambiental (EA) vem crescendo em seus encontros de pesquisa. É possível localizar nesses encontros trabalhos que discutem as produções do próprio campo. Para exemplificar, citamos três trabalhos apresentados no EPEA (2007) e dois na ANPESUL (2008). Lustosa, Matos e Loureiro (2007) analisam os documentos do V Fórum Brasileiro de Educação Ambiental, realizado em 2005, em Goiás, procurando responder às questões sobre os atores sociais nele envolvidos e as temáticas em desenvolvimento problematizadas e trabalhadas nessas produções. Lorenzetti e Delizoicov (2007) discutem as dissertações produzidas nesse campo, no período de 1997 a 2005, desenvolvidas num mestrado em Educação Ambiental na Região Sul. Daniel e Marin (2007) analisam os referenciais teórico-metodológicos nas pesquisas em EA em contexto escolar presentes em dois periódicos e em eventos da área.

Dois trabalhos apresentados na ANPESUL (CARVALHO; SCHMIDT, 2008; GUERRA, 2008) analisam diferentes eventos, entre eles a ANPEd nacional e a regional. Guerra (2008) faz o levantamento dos atores participantes dos eventos de pesquisa em Educação 
Ambiental da Região Sul. A sua preocupação volta-se mais para o crescimento quantitativo e a formação dos grupos. Carvalho e Schmidt (2008) manifestam interesse pela análise do campo científico, considerando a origem de seus participantes, gênero, titulação, instituições, origem geográfica dos trabalhos e os principais eixos temáticos. Porém, as análises desses trabalhos não consideram os aspectos qualitativos e formais. Elas demonstram a emergência da pesquisa em EA, a existência de distintos enfoques no tratamento das questões ambientais e apontam a necessidade de estudos para caracterizar as pesquisas realizadas.

A análise da produção desses trabalhos também é debatida em coletâneas por Pedrini e De-Paula (1997), Sato e Santos (2003) e Sauvé (2005), entre outros. Pedrini e De-Paula (1997), ao analisarem o II e o III EEA, detectam nos trabalhos confusões, quando não ausências, de natureza conceitual e metodológica. Sato e Santos discutem as tendências teóricas e metodológicas da pesquisa em EA. Sauvé (2005), ao explorar bancos de dados americanos e europeus, destaca quinze correntes discursivas na EA. Buscar os elementos integradores, que promovem a unidade sem anular a diversidade, é uma preocupação constante da área de pesquisa (SATO; SANTOS, 2003). Porém, menos frequente, no Brasil, é encontrar artigos em revistas da área sobre a temática.

A análise de um evento possui uma dimensão retrospectiva, que se volta para o passado com um olhar avaliativo crítico e uma projetiva voltada para o futuro, buscando ampliar o campo da pesquisa e o crescimento quantitativo e qualitativo da comunidade. Com este artigo pretende-se contribuir para o debate e o fortalecimento das pesquisas em EA, focalizando a natureza dos textos e objetivos presentes nos trabalhos completos dos eventos regionais de EA. Procura-se responder a questões sobre se esses trabalhos apresentados nos eventos derivam do planejamento de pesquisa ou de estudos retrospectivos; se a natureza dos textos e os seus objetivos traduzem a intencionalidade e a qualidade das pesquisas em EA.

A coleta e análise das informações se fundamentam nos princípios da pesquisa documental e análise de conteúdos. O texto 
apresenta parte das informações que estão sendo processadas pelo Grupo de Estudos e Pesquisa em Educação Ambiental da Universidade Estadual de Ponta Grossa, com os seguintes objetivos: analisar a natureza dos textos e os objetivos dos trabalhos apresentados em eventos regionais de pesquisa no Brasil; avaliar a intencionalidade e o planejamento de pesquisa a partir das modalidades textuais e dos objetivos dos trabalhos.

As hipóteses que conduzem o artigo são duas: a) os eventos regionais caracterizam-se pela diversidade de participantes, interesses e ligações variáveis com a prática da pesquisa, expressos em seus textos, nas modalidades textuais e nos seus objetivos de pesquisa; b) a natureza textual e os objetivos presentes nos trabalhos dos eventos regionais expressam a diversidade de concepções, estágios e graus de planejamento da pesquisa. Espera-se, assim, que, mediante a análise e a discussão do caráter formal da natureza textual e dos objetivos dessas produções, possa-se contribuir para a qualidade e fortalecimento interno da pesquisa em EA como para o reconhecimento externo de outras comunidades de pesquisadores.

\section{Educação Ambiental como construção de um campo científico}

Como dimensão ambiental do processo educativo, a Educação Ambiental tem "a possibilidade de lidar com conexões entre diferentes dimensões humanas, possibilitando entrelaçamentos e trânsitos entre múltiplos saberes" (JACOBI, 2005, p. 244). Como objeto de pesquisa fundado na interface das ciências ambiental, humanas e sociais, é mais bem estudada, explicada e constituída se for capaz de integrar os conhecimentos diversos e complementares em novos procedimentos metodológicos.

Por derivar de campos de conhecimentos complexos ambiental e humano, em ações recíprocas que modificam simultaneamente o ambiente e as relações sociais -, a EA se constitui num campo de conhecimento duplamente complexo. Mais que isso, torna-se um projeto de conhecimento em que as suas ações, para se concretizarem, demandariam esforço conjunto do saber e do ser em mútuas relações constitutivas; de conhecimentos que necessitam 
ultrapassar as fronteiras disciplinares e seguir caminhos multi, inter e transdisciplinares. Por ser projeto, encerra simultaneamente a negação de um quadro teórico-metodológico e a afirmação do desejo de construir um novo tópos; nega e busca superar as ciências ambientais e sociais estabelecidas, afirmando a utopia do homem consciente de si em suas relações com os outros homens e com a natureza (FLORIANI, 2006; ROSSO, 2007).

Dessa forma, a EA se constitui numa zona de contato, caracterizada por Santos (2004, p. 809) como "campos sociais onde diferentes mundos-da-vida normativos, práticas e conhecimentos se encontram, chocam e interagem". As zonas de contato "são sempre seletivas, porque os saberes e práticas excedem o que de uns e outros é posto em contato". O que é posto em relação não são os núcleos centrais, mas as periferias, por isso a construção de conhecimentos na zona de contato segue sempre caminhos emergentes - nas palavras de Sato, Gauthier e Parigipe (2005), provisórios, heterogêneos e heterodoxos. Isso reclama uma "atitude inovadora de cooperação sistemática entre diversas áreas do conhecimento humano" para desenvolver uma nova cultura científica (ROCHA, 2003, p. 158), que não ocorrerá sem conflitos e resistências filosóficas e institucionais, ancorados em interesses estabelecidos. Essa nova cultura necessita avançar no "julgamento dos pares", que traz em si o risco de cumplicidade e da falta de visão crítica, e no "julgamento dos ímpares”, que necessitam ser convencidos a partir de métodos e procedimentos conhecidos (BURSZTYN, 1999).

É a luta para a constituição de um campo científico. Essa luta dá-se, simultaneamente, em duas frentes, a das especificidades do seu objeto de conhecimento e a das pressões da sociedade global que o envolve, fazendo com que a sua autonomia seja relativa e dentro das regras do campo científico. Como tal, para Bourdieu é uma luta em que "não se pode triunfar sobre os adversários sem empregar contra eles as armas da ciência, contribuindo assim para o progresso da verdade científica" (BOURDIEU, 1994, p. 25). Assim, debruçar-se sobre as produções da EA, mediante a análise dos trabalhos apresentados, pode favorecer a sua estruturação e desenvolvimento, pois toda crítica 
empreendida contra um campo ou comunidade científica, seja de origem interna ou externa, dos pares ou dos ímpares, reforça a própria ciência e o seu campo científico.

A EA, como objeto em permanente constituição, ou projeto, entre o campo científico natural e os campos humano e social, será firmada como um campo reconhecido se atender aos critérios formais particulares, estabelecidos nos campos de que deriva. Não será, apenas, por sua lógica interna, menos ainda por processos militantes e voluntariosos, mas como resposta ao desafio de fortalecer-se internamente ou entre os "pares", empreendendo uma avaliação, levando em consideração as projeções e as expectativas feitas para o novo campo e externamente, pelo convencimento dos "ímpares" situados nos campos científicos fronteiriços. Isso contribuiria para o fortalecimento e a autonomia da EA, conferindo-lhe maior poder de refração e de retradução frente às pressões externas de "princípios heterônomos" que dificultam o diálogo e o debate entre as diversas produções (BOURDIEU, 2004, p. 22).

As divergências e as exclusões mútuas entre os conhecimentos distintos e heterogêneos que constituem sua zona de contato, postos como antagônicos, produzem reducionismos teóricos. De um lado, o "social pode ser absorvido por enfoques e visões biologistas, ou por um energitismo social que pretende unificar os processos biossociais em função de seus fluxos energéticos" (LEFF, 2002, p. 227). Os desconhecimentos entre os campos de conhecimento constitutivos da EA têm orientado visões ingênuas, individualistas e voluntaristas, por estarem desconectadas de qualquer conteúdo científico social ou ambiental. Ingênuas por imaginarem que a EA possa vencer sozinha o regime social de produção, desconsiderando a ambivalência da educação, que tanto produz libertação e transformação quanto doutrinação e conformação social. Individualistas por apostarem que os sujeitos isolados - fazendo a sua parte ou agindo localmente conseguem reverter quadros global e socialmente instituídos. Noutro extremo, estão as versões conservacionistas e voluntaristas que não levam em conta as singularidades e propriedades das comunidades humanas, descuidando das dimensões políticas, éticas e culturais. Por 
isso, o avanço e o crescimento da EA estão ligados ao esforço empreendido para pôr em prática sua integração sempre emergente e projetiva (FLORIANI, 2006; JACOBI, 2005; LEFF, 2002; MEDEIROS; BELLINI, 2001; REIGOTA, 2007; SAUVÉ, 2005).

Se a discussão das produções de pesquisa visa antes de tudo a uma crítica do que se produz, ela também chama a atenção para elementos que necessitam ser superados e construídos. Não se trata de estabelecer um horizonte paradigmático e normativo para a EA, com definição dos campos teóricos e metodológicos, mas de apresentar elementos para o debate. A EA entendida como objeto de conhecimento duplamente complexo e relacional, ou como uma zona de contato (SANTOS, 2004), não é passível de ser reduzida ao represamento metodológico e teórico (MORIN, 1998) ou paradigmático em seu sentido estrito (KUHN, 1990). Nesse contexto, o melhor é "incitar a estratégia/inteligência do sujeito pesquisador a considerar a complexidade da questão" (MORIN, 1998, p. 334) e abrir mão de qualquer tendência fácil e apressada de unificação teóricometodológica.

O ambiente como integrante da complexidade "não é um objeto perdido no processo de diferenciação e especialização das ciências e, por isso, não é reintegrável pelo intercâmbio interdisciplinar dos conhecimentos existentes". Mas é "uma falta insaciável de conhecimento", pois o próprio conceito de ambiente escapa aos padrões científicos empiristas (LEFF, 2004). O segundo elemento complexo que habita a EA é o ser humano. "A sua complexidade não se reduz ao reflexo de uma realidade complexa no pensamento" (LEFF, 2004, p. 48 e 70). Por sua natureza, essa complexidade não pode ser ignorada e simplificada na EA, reduzindo-a a "ações de conscientização dos cidadãos e à inserção de 'componentes' de capacitação dentro de projetos de gestão ambiental orientados por critérios de rentabilidade econômica" (LEFF, 2002, p. 223).

A construção dos conhecimentos de EA, como campo emergente, não derivado dos já instituídos, se constitui progressivamente em clima de persistente debate e trocas de conhecimentos e atores heterogêneos no movimento histórico. Por 
isso, necessita fundar-se uma teoria plural e aberta que, mais que explicar e fazer previsões, compreenda, integre e modifique simultaneamente os sujeitos e os objetos de conhecimento. O que confere à temática tais características é o conteúdo intelectual, "a pertinência" do capital simbólico acumulado tanto dos pressupostos teóricos quanto dos seus métodos. Os pesquisadores e educadores ambientais têm respondido a esse desafio, apesar das dificuldades encontradas (REIGOTA, 2007).

Assim, o debate sobre as produções de pesquisa pode conter a preocupação formal das contribuições efetivas para solucionar os problemas enfrentados na pesquisa. Qual é a contribuição de um evento de pesquisa para o desenvolvimento do campo científico? Espera-se que o evento mostre o que está sendo produzido e instaure o debate dessas produções, congregue não só os experts do campo de pesquisa, mas também os neófitos, recém-chegados. Dos experts espera-se a comunicação de trabalhos de pesquisa e paciência pedagógica com as primeiras incursões e resultados dos neófitos; porém, de ambos se espera o debate.

\section{Demarcações teórico-metodológicas}

A pesquisa caracteriza-se como documental com a análise de conteúdo. A pesquisa documental considera documento:

Qualquer suporte que contenha informação registrada, formando uma unidade, que possa servir para consulta, estudo ou prova. Inclui impressos, manuscritos, registros audiovisuais e sonoros, imagens, sem modificações, independentemente do período decorrido desde a primeira publicação (ABNT/NBR 6023, 2000).

Assim, as versões eletrônicas dos encontros se constituíram nos documentos processados e analisados. Para realizar essas operações, foram seguidas as orientações de Bardin (2004) quanto à procedência da análise de conteúdo. O processamento da informação foi realizado a partir do emprego da tríplice leitura, feita pelos participantes do grupo, e do fichamento dos trabalhos completos. Após o término dessa etapa, 
procedeu-se à troca de material para a discussão e conferência das informações do texto para a ficha definitiva. Ao final do processo, as fichas integravam um banco de dados gerenciado por um participante do grupo.

Cada trabalho foi acompanhado de ficha de leitura contendo os seguintes elementos: referência do trabalho, palavras-chave, problema de pesquisa, questões de pesquisa, objetivos, hipótese(s), metodologia, população investigada, resultados, conclusões, questões em aberto e referências utilizadas no texto. Para a discussão dos objetivos, formouse um novo banco de dados contendo as seguintes informações: o número do artigo conforme a ordem dos textos, a referência do texto, a natureza do texto e seu(s) objetivo(s).

Para classificar os trabalhos segundo a natureza, relato, ensaio e pesquisa, foram retomados os textos iniciais e considerada a presença de elementos teóricos e empíricos e dos definidores das ações de pesquisa, como problemas, objetivos, metodologia e análise de informações. Os trabalhos apresentados no VII Encontro de Educação Ambiental do Estado do Rio de Janeiro (VII EEA-RJ), realizado no ano de 2003, foram processados e analisados em 2005 e 2006. As informações do IX EPEA-PR, a partir da sua versão em CD, foram processadas e analisadas em 2007.

No corpo teórico para a análise, consideramos inicialmente a natureza dos trabalhos de um evento de pesquisa, como ensaios, relatos de experiência e pesquisa. A seguir explicitaremos a questão dos objetivos de pesquisa como um constituinte formal de um texto de pesquisa e um delimitador do âmbito da investigação. Para finalizar a demarcação, será apresentada uma distinção entre estar em pesquisa e fazer pesquisa. Para definirmos as modalidades de participação em eventos, recorremos às normas para publicação em revistas e eventos e para a tipificação dos objetivos de pesquisa estabelecidos no artigo de Larocca, Rosso e Souza (2005).

Os relatos podem ser tanto de experiência ou caso como de pesquisa. Os primeiros descrevem experiência individual ou coletiva de proposta de intervenção, indicando as condições de realização da experiência relatada. Diferem de um trabalho de pesquisa por seu 
caráter mais livre da intencionalidade e planejamento da pesquisa e por centrarem-se mais na apresentação das ações desenvolvidas. $O$ seu destaque está na demonstração de resultados alcançados e de lições aprendidas, principalmente do ponto de vista prático e estratégico, sem necessidade de estarem simultaneamente ancorados nas questões teóricas e metodológicas. Por vezes, a metodologia se refere mais aos passos e às sequências das ações do que aos procedimentos e cuidados na tomada dos registros e análise das informações. Já um relato de pesquisa, concluída ou em andamento, prioriza a divulgação de dados empíricos, metodologia, resultados e discussão das informações.

Se, de um lado, os relatos enfatizam a experiência e a prática, do outro, a ênfase dos ensaios está no seu caráter de discussão teórica argumentativa e reflexiva - sem a obrigatoriedade da análise de informações de pesquisa. Por ser de natureza teórica, o ensaio deve ser claro e conciso para validar o objetivo da tese a ser defendida. Esse tipo de trabalho possui um padrão estrutural que corresponde aos seguintes elementos: formulação do problema e sua importância, tese de defesa, argumentos a favor da proposta, objeção da defesa, resposta a essas objeções e conclusões do autor. No fundo, o ensaio representa sempre um debate entre o conhecimento já detido pelo autor e aquilo que ele pretende conhecer.

Os trabalhos de pesquisa, segundo orientação da ANPEd, não são "textos que se restrinjam a capítulos de tese ou dissertação, revisão bibliográfica ou relato de experiência", mas devem apresentar "consistência e o rigor da abordagem teórico-metodológica". Assim, um trabalho de pesquisa deve integrar de forma consistente e rigorosa tanto elementos teóricos quanto metodológicos. Um trabalho de pesquisa se diferencia do relato e do ensaio pela profundidade, rigor e integração no tratamento das questões teórico-metodológicas. Completando a definição do trabalho, a $30^{\text {a }}$ Reunião Anual da ANPEd (2007) explicita os critérios de julgamento:

Relevância e pertinência do trabalho para a área de pesquisa.

Riqueza conceitual na colocação dos problemas. 
Consistência e rigor na abordagem teórico-metodológica e na argumentação.

Interlocução com a produção da área.

Originalidade na contribuição para a área.

Após demarcarmos as modalidades de trabalhos que podem ser encontradas nos eventos, passaremos a apresentar o marco teórico que definirá as modalidades de objetivos.

A definição de um objetivo de pesquisa se expressa a partir da formulação de um problema de pesquisa, sua contextualização e projeção de ações para responder ao problema. A falta de segurança na definição do problema de pesquisa vai se refletir nos objetivos formulados. Embora possa ser admitido o caráter inicial - aproximativo e progressivo - da constituição de um problema de pesquisa, com o desenrolar da própria pesquisa, possibilitando ajustes, isso de forma alguma livra o seu autor, ao relatar os resultados, da necessidade do rigor. Este não se atinge com a rigidez do método, mas com uma estratégia de adaptação permanente. Assim, o objetivo pode explicar o caráter da pesquisa, a começar pelo modo como o pesquisador determina, da mesma forma, expressar a maturidade de sua trajetória investigativa (POOLI, 1998).

Portanto, a análise dos objetivos de uma investigação, antes de expressar a perícia na aplicação do método, é a expressão do desvelamento do objeto de pesquisa. Nesse sentido, Larocca, Rosso e Souza (2005) sugeriram as seguintes categorias de objetivos: objetivos generalistas, objetivos meios e exploratórios, propositivos, descritivos, avaliativos e compreensivos. A apresentação dos tipos de objetivos integrará elementos presentes nos textos do $\mathrm{EEA}^{-\mathrm{RJ}^{7}}$ para a sua exemplificação.

Os objetivos generalistas são aqueles em que não é possível estabelecer uma limitação mais ou menos precisa, como "dar às atividades propostas maior respaldo teórico, tornando mais claramente definida a concepção de natureza que embasa o projeto” (p. 413), ou

7 Os números das páginas, indicados entre parênteses, correspondem à versão eletrônica do arquivo recebido do evento. 
"despertar o senso de responsabilidade e cidadania" (p. 322). Objetivos meios referem-se a uma etapa que antecede a pesquisa propriamente dita, como "tecer algumas considerações sobre a proposta de uma educação ambiental participativa” (p. 267).

Os objetivos meios ou exploratórios buscam uma aproximação com o fenômeno, pelo levantamento de informações que poderão levar o pesquisador a conhecer mais a seu respeito e encaminhar ações mais precisas. A sua concretização não expressa um resultado de pesquisa propriamente dito, mas uma condição para o planejamento de uma pesquisa. Assim, é comum nessa categoria encontrarmos objetivos do tipo "fazer um estudo", "levantar práticas", entre outros.

Os objetivos de natureza propositiva são os que se preocupam com a apresentação de sugestões e propostas, como o de "propor uma possibilidade mais crítica do uso de recursos computacionais para atender às necessidades da educação ambiental [...]" (p. 395), ou "despertar os educandos e educadores para participarem de problemas com os quais convivem no ambiente em que vivem" (p. 163).

Os objetivos descritivos caracterizam-se pela preocupação predominante de fazer um relato detalhado de ações e procedimentos, como o de "descrever como foi desenvolvida a atividade de recebimento de anais pelo Espaço da Ciência, sua importância para a preservação e perpetuação de espécies ameaçadas [...]” (p. 215), ou de "relatar os primeiros passos percorridos na formação de uma Rede de Educação Ambiental na região [...]” (p. 277).

Os objetivos avaliativos destacam-se por suas finalidades valorativas, como "buscar uma melhor compreensão e interpretação das motivações e expectativas, que levam os indivíduos a privilegiarem a escolha de um ambiente natural como elemento central de lazer em detrimento de outras atividades" (p. 248) e "mapear o tipo de público que visita, e o que vai buscar no Parque, aproveitando sua estada para despertar-lhe interesse pelos diversos saberes existentes" (p. 440).

$\mathrm{E}$, finalmente, os objetivos compreensivos destinam-se a interpretar uma dada realidade ou problema mais amplo, como, por exemplo, "entender o universo representacional dos educadores ambientais de ONGs ambientalistas do Rio de Janeiro [...]" (p. 363) e 
"compreender os processos que $\mathrm{t}[\hat{\mathrm{e}}] \mathrm{m}$ se desenvolvido na comunidade [...] com a criação e implementação da [...] APA Municipal” (p. 223).

Para responder a questionamentos sobre esses trabalhos apresentados nos eventos - se eles derivam do planejamento de pesquisa ou de estudos retrospectivos e se a natureza dos textos e os seus objetivos traduzem a intencionalidade das pesquisas em EA -, buscamos o auxílio de Beillerot (1991, apud LENOIR, 2006, p. 13031304), que esclarece essa questão através da distinção entre o "estar em pesquisa" e o "fazer pesquisa":

Estar em pesquisa, precisa Beillerot, é refletir sobre problemas, sobre dificuldades encontradas; é se esforçar para descobrir respostas às questões que nos colocamos. Trata-se, portanto, de um trabalho reflexivo sobre as atividades da nossa vida pessoal, social, familiar ou profissional. Em suma, trata-se de um trabalho reflexivo sobre nossas práticas, sobre nossas experiências (LENOIR, 2006, p. 1303-1304).

Subjacentes a essa distinção, encontram-se, entre outros elementos: as origens da pesquisa, se do contexto acadêmico ou da prática dos educadores e ambientalistas; as diferentes maneiras de fazer uma pesquisa, se voltada para um caso ou uma prática específica ou procurando estabelecer generalização; as metas da pesquisa, se contribuir para a solução problemas concretos ou estabelecer contribuição teórica; os diferentes auditórios, se voltada para outros educadores e atores de EA ou para o debate da comunidade acadêmica (SANTOS, 1989). Nos procedimentos de pesquisa com uma perspectiva prática, os educadores ambientais desejam aprofundar conhecimentos e desenvolver sua prática através da pesquisa (BROWN, 2008, p. 10-12). Esse enfoque não pode ser desprezado por não atender integralmente aos parâmetros que orientam a pesquisa em sentido acadêmico restrito; o seu processo de inferência, realizado a partir de experiências pessoais e aplicado a um dado contexto, é da maior importância para a EA. Ele é portador de um processo reflexivo que, na formação profissional, promove inovação e diversidade das práticas, tão necessárias num campo científico formado por uma zona de contatos. 
O "fazer pesquisa", de um ponto de vista científico, repousa nos "meios de uma objetivação das questões e das preocupações para poder estudá-los", implicando três condições fundamentais: produção de novos conhecimentos, processo rigoroso de investigação e comunicação dos resultados. A segunda condição - processo rigoroso de investigação - implica crítica, reflexão e compromisso com a replicação dos resultados. Atingir esses critérios exige um diálogo teórico e metodológico, uma comparação crítica com os estudos anteriores e a abertura a novos debates.

A seguir apresentamos a análise quantitativa das informações analisadas e tabuladas.

Em quatro dos 62 trabalhos do EEA-RJ, não foi possível identificar os objetivos e em outros três foi necessário fazer leituras repetidas para retirá-los do contexto geral do texto. Quanto à natureza, 16 trabalhos foram classificados como ensaios, 25, como relatos e 21 como pesquisas. Nos ensaios e nos relatos, predominam os objetivos generalistas e propositivos; já nos trabalhos de pesquisa, seis textos apresentam objetivos generalistas ou propositivos, indicando indefinições na condução da pesquisa ou em seu caráter de intervenção.

Dos 77 trabalhos completos apresentados nos anais do IX EPEA-PR de 2006, foram encontrados 15 ensaios, 27 relatos e 35 trabalhos de pesquisa. Apesar de apresentarem proporcionalmente maior número de trabalhos de pesquisa, apenas 18 destes continham objetivos com caráter de pesquisa, indicando uma tendência maior do caráter propositivo e de intervenções. Isso sinaliza para a indefinição das pesquisas ou da compreensão de seu conceito. Pouco mais da metade dos trabalhos possui objetivos avaliativos, compreensivos, descritivos e objetivos meios, que, em sentido lato, poderão constituirse em pesquisas.

Como integrantes da pesquisa, esses objetivos são encontrados também nos trabalhos classificados como ensaios e relatos. Tal fato sugere que textos a priori não classificados na categoria de pesquisa podem estar estreitamente ligados a ela, ao passo que textos classificados como de pesquisa podem ainda não ser portadores dessa definição. Pode-se também creditar a segunda limitação à imperícia, 
falta de orientação ou às dificuldades de escrita dos iniciantes na pesquisa.

Tabela 1 - Trabalhos apresentados no VII EEA-RJ (2003) e no IX EPEA-PR (2006)

\begin{tabular}{l|c|c|c|c|c|c|c|c}
\cline { 2 - 11 } \multicolumn{1}{c}{ Objetivos } & \multicolumn{2}{c}{ Pesquisa } & \multicolumn{2}{c}{ Ensaios } & \multicolumn{2}{c}{ Relatos } & \multicolumn{2}{c}{ Total } \\
\hline Evento & RJ & PR & RJ & PR & RJ & PR & RJ & PR \\
\hline Sem objetivo & 0 & 1 & 1 & 1 & 2 & 0 & $\mathbf{3}$ & $\mathbf{2}$ \\
\hline Generalista & 3 & 3 & 8 & 4 & 6 & 5 & $\mathbf{1 7}$ & $\mathbf{1 2}$ \\
\hline Propositivo & 3 & 13 & 4 & 4 & 10 & 5 & $\mathbf{1 7}$ & $\mathbf{2 2}$ \\
\hline Objetivo meio & 1 & 5 & 2 & 4 & 0 & 7 & $\mathbf{3}$ & $\mathbf{1 6}$ \\
\hline Descritivo & 3 & 3 & 0 & 4 & 4 & 4 & 4 & $\mathbf{8}$ \\
\hline Compreensivo & 11 & 5 & 0 & 4 & 0 & 1 & $\mathbf{1 1}$ & $\mathbf{6}$ \\
\hline Avaliativo & 3 & 5 & 1 & 1 & 3 & 5 & $\mathbf{7}$ & $\mathbf{1 1}$ \\
\hline \multicolumn{1}{c}{ Total/categoria } & 21 & 35 & 16 & 15 & 25 & 27 & $\mathbf{6 2}$ & $\mathbf{7 7}$ \\
\hline
\end{tabular}

Levando em consideração a natureza dos textos e o total de objetivos de pesquisa, tomados em seu sentido lato e presentes em cada categoria textual, os dados estão agrupados na Tabela II.

Tabela 2 - Total de trabalhos apresentados no VII EEA-RJ e no IX EPEA$\mathrm{PR}$, considerando os objetivos de pesquisa em função da natureza dos textos completos analisados.

\begin{tabular}{c|c|c|c}
\hline $\begin{array}{c}\text { Natureza dos } \\
\text { trabalhos }\end{array}$ & Trabalhos & $\begin{array}{c}\text { Com objetivos de } \\
\text { pesquisa }\end{array}$ & $\begin{array}{c}\text { Considerando o } \\
\text { total dos trabalhos }\end{array}$ \\
\hline Pesquisa & 56 & 33 & $23,74 \%$ \\
\hline Relato & 52 & 24 & $17,27 \%$ \\
\hline Ensaio & 31 & 9 & $6,47 \%$ \\
\hline Total & 139 & 66 & $47,48 \%$ \\
\hline
\end{tabular}

Entre os 66 trabalhos com objetivos de pesquisa, 33 ou 23,74\% são trabalhos de pesquisa, 24 ou $17,27 \%$ são relatos e 9 ou $6,47 \%$ são 
ensaios. Do total de 139 trabalhos completos analisados nos dois eventos, encontramos 66 objetivos de pesquisa mencionados, que correspondem a 47,48 \% dos objetivos dos trabalhos apresentados nos referidos eventos.

Já quando os trabalhos são tomados dentro das categorias, nos 56 trabalhos classificados como pesquisa, ou 40,28\% do total de trabalhos, são encontrados 33 ou 58,92\% com objetivos de pesquisa, ou seja, pouco mais da metade dos trabalhos classificados como de pesquisa possui objetivos de pesquisa. Esses objetivos correspondem a $23,74 \%$ do total dos objetivos dos trabalhos classificados como de pesquisa, indicando um objeto de pesquisa em constituição. Tal situação é considerada como integrante da constituição dos objetos de pesquisa.

Dos 52 relatos, encontramos 24 ou 46,15\% com objetivos de pesquisa, que correspondem a $17,27 \%$ do total de trabalhos. O fato de esses relatos apresentarem objetivos de pesquisa possivelmente indica uma migração das formas de intervenção para a constituição de objetos de pesquisa, ou seja, relatos com características potenciais para se constituírem em projetos de pesquisa. Isso pode traduzir uma condição operacional do educador ambiental de "estar em pesquisa", refletindo sobre as questões práticas e os problemas que emergem das atividades de EA, diferentemente da situação esperada de "fazer pesquisa" (BEILLEROT, 1991, apud LENOIR, 2006, p. 1303).

Então, poderíamos dizer que o "estar em pesquisa" e o "fazer pesquisa" apresentam uma diferença básica no que diz respeito ao ponto de partida de um trabalho de pesquisa. Ambos caracterizam-se fortemente pela ideia de pesquisa como processo, mas o "estar em pesquisa" revela a ideia de partir da experiência, da vivência, e o "fazer pesquisa" parte da premissa da necessidade de objetivação e sistematização dos dados sobre a realidade para depois estudá-la.

Dos 31 ensaios, ou 22,31\% do total de trabalhos, foram identificados 9 ou 6,47 \% que são trabalhos com objetivos de pesquisa, indicando ligações de um objeto de pesquisa, porém, em fase inicial de desenvolvimento. Esses trabalhos não contêm ainda sustentação empírica, mas podem estar associados à dinâmica do "fazer pesquisa". 
O conjunto dessas informações indica que em uma análise mais detalhada dos textos, a partir dos seus objetivos, nem todo trabalho com dados empíricos possui uma definição clara de pesquisa. E trabalhos que não se classificam como tal podem ter origem de pesquisa ou virem a se constituir num objeto de pesquisa. Essas informações sinalizam a imaturidade e/ou planejamento inadequado das pesquisas, expressos nos insuficientes $47,48 \%$, ou seja, em menos da metade dos trabalhos dos dois eventos, como portadores de objetivos de pesquisa. São limitações formais na apresentação dos textos, inconsistências na condução das investigações, ou falta de orientação desses trabalhos.

\section{Considerações finais}

Os eventos regionais de Educação Ambiental representam espaços múltiplos de circulação de ideias e debate. São híbridos nos quais são apresentados relatos de experiências, de pesquisa e ensaios, e nesses espaços convivem as militâncias ecológicas com ações educativas. Por sua proximidade com a formação inicial para a pesquisa, mostram iniciativas inovadoras e também os limites das primeiras incursões.

As limitações presentes nos textos dos eventos avaliados não diferem das identificadas por Greca, Costa e Moreira (2002) sobre o III ENPEC, promovido pela Associação Brasileira de Pesquisa em Educação em Ciências na definição do problema, no esclarecimento da metodologia, em que apenas dos trabalhos apresentam os resultados coerentemente com o problema definido e com os referenciais teóricos e metodológicos adotados. Essa situação é definida por Alves-Mazzotti (2001, p. 40) como de "pobreza teórico-metodológica". Dadas às particularidades dos recortes investigativos e metodológicos, a análise efetuada converge com esses diagnósticos ao identificar que aproximadamente $52 \%$ do total de trabalhos são classificados dentro das categorias ensaio e relato e em aproximadamente metade dos trabalhos de pesquisa não há objetivos que possam ser caracterizados como de pesquisa. Essa situação é identificada como um dos fatores a que se atribui o pouco retorno das pesquisas sobre as práticas em educação (ANDRÉ, 2001; MIRANDA; RESENDE, 2006; MORAES, 2004; WARDE, 1990).

A relação existente entre a natureza dos textos e os objetivos de pesquisa deve ser relativizada. Os objetivos de pesquisa são 
encontrados em maior proporção nos trabalhos de pesquisa, em segundo lugar nos relatos e em terceiro nos ensaios. Apesar de os objetivos de pesquisa serem mais frequentes nos trabalhos de pesquisa, a sua frequência não atinge a totalidade desses trabalhos. Os relatos, mesmo que não tenham uma demarcação teórica, podem expressar uma dimensão teórica da realidade material. Os ensaios, por sua vez, não deixarão de manifestar uma forma particular de conceituar a realidade pela falta de informações empíricas. No entendimento integrado de teoria-empiria, deixa de ser significativa a separação dos conceitos e dos fatos da observação, pois a teoria não é só “o conhecimento que se produz", mas é, principalmente, “o modo como se produz” (SANTOS, 1989, p. 72).

A categorização dos trabalhos a partir da natureza textual e dos seus objetivos atende aos aspectos formais dos trabalhos e não pode ser tomada como critério de qualidade das pesquisas. Apenas pode ser um indicador necessário, porém insuficiente, de uma pesquisa bem conduzida e adequada à prática. Disso pode resultar um paradoxo em que trabalhos com ideias inovadoras possam ser esquecidos por seus limites formais e trabalhos bem demarcados formalmente não tragam nenhuma contribuição ao campo.

A qualidade formal dos textos e resumos é condição fundamental para a constituição de bancos de dados, de sistemas de buscas, contribuindo para aprofundar o debate teórico-metodológico e a identificação de temas emergentes ou saturados. Os eventos locais, mesmo apresentando contingências, contribuem para o debate e a formação direta de seus participantes, mas podem perder espaço quando se trata de promover o diálogo com outros grupos. Tal fato reforça a necessidade de qualidade formal dos textos como bases de dados confiáveis para as consultas da comunidade de educadores ambientais e da sociedade.

Nos eventos avaliados, é comum a diversidade de padrões textuais, das relações entre elementos teóricos e empíricos e do planejamento e relatório das investigações. Expressam a produção de uma comunidade científica em formação, integrando diferentes graus de envolvimento na pesquisa e de formação. São contingências a serem 
acompanhadas na organização dos eventos. Os eventos regionais, ao contemplarem diferentes modalidades de participação, se constituem num espaço de formação de pesquisadores e educadores ambientais. A dimensão de pesquisa firma-se nas discussões e trocas de experiências na constituição de uma comunidade de pesquisadores e também nos produtos apresentados apoiados no rigor, na qualidade científica e na pertinência dos seus resultados.

Da investigação é possível apontar algumas implicações que podem se constituir em cuidados dos organizadores dos eventos de EA, como: orientações para a apresentação dos textos; divulgação dos critérios de avaliação dos trabalhos; cronograma com margem de tempo suficiente para a inscrição e avaliação dos textos; formação de comitês com número suficiente de avaliadores; previsão de modalidades e espaços diferenciados de comunicação, entre outras iniciativas que contribuem para ampliar a qualidade das produções apresentadas nos eventos, e manutenção, em site próprio e permanente, das produções dos encontros.

\section{Referências}

ABNT - ASSOCIAÇÃO BRASILEIRA DE NORMAS TÉCNICAS. NBR 6023: informação e documentação - referências - elaboração. São Paulo: ABNT, 2000.

ALVES-MAZOTTI, Alda Judith. Relevância e aplicabilidade da pesquisa em educação. Cadernos de Pesquisa, São Paulo, n. 113, p. 39-50, jul. 2001.

ANDRÉ, Marli E. Dalmazo Afonso de. Pesquisa em Educação: buscando rigor e qualidade. Cadernos de Pesquisa, São Paulo, n. 113, p. 51-64, jul. 2001.

ANPED - ASSOCIAÇÃO NACIONAL DE PESQUISA EM EDUCAÇÃO. Trabalhos. Disponível em: http://www.anped.org.br/reunioes/30ra/index.htm. Acesso em: 25 maio 2009.

BARDIN, Laurence. Análise de conteído. 3. ed. Lisboa: Edições 70, 2004.

BOURDIEU, Pierre. Lições da aula. Tradução de Egon de Oliveira Rangel. 2. ed. São Paulo: Ática, 1994.

Os usos sociais da ciência: por uma sociologia clínica do campo científico. Tradução de Denice Barbara Catani. São Paulo: UNESP, 2004. 
BROWN, Andrew. O ensino da pesquisa para a diversidade da pesquisa em educação. Tradução de Verônica van Wilpe. Revisão técnica e notas de Jefferson Mainardes. Práxis Educativa, Ponta Grossa, v. 3, n. 1, p. 9-16, jan./jun. 2008.

BURSZTYN, Marcel. Interdisciplinaridade: é hora de institucionalizar! Ambiente \& Sociedade, Campinas, v. 2, n. 5, p. 229-231, jul./dez. 1999.

CARVALHO, Isabel Cristina de Moura; SCHMIDT, Leticia Santos. A pesquisa em Educação Ambiental: uma análise dos trabalhos apresentados na ANPEd, ANPPAS e EPEA de 2001 a 2006. ANPEd-Sul - VI Seminário de Pesquisa em Educação da Região Sul. UNIVALI, Itajaí, 2008, p. 1-19.

DANIEL, Michelle Hudson; MARIN, Andreia A. Referenciais teórico-metodológicos nas pesquisas em educação ambiental no ambiente escolar. In: IV Encontro de Pesquisa em Educação Ambiental, 2007, Rio Claro. "Questões Epistemológicas Contemporâneas: o debate modernidade e pós-modernidade. Rio Claro, 2007. v. 1. p. 1-12.

DIAZ ROCHA, Paulo E. Trajetórias e perspectivas da interdisciplinaridade ambiental na pós-graduação brasileira. Ambiente \& Sociedade, Campinas, v. 6, n. 2, p. 155-179, jul./dez. 2003.

FLORIANI, Dimas. Ciências em trânsito, objetos complexos: práticas e discursos socioambientais. Ambiente \& Sociedade, Campinas, v. 9, n. 1, p. 65-80, jan./jun. 2006.

GRECA, Ileana María; COSTA, Sayonara S. Cabral da; MOREIRA, Marco Aantonio. Análise descritiva e crítica dos trabalhos de pesquisa submetidos ao III ENPEC. Revista Brasileira de Pesquisa em Educação em Ciências, Belo Horizonte, v. 2, n. 1, p. 73-82, 2002.

GUERRA, Antonio Fernando Silveira. Um panorama da inserção da Educação Ambiental na região sul. ANPEd-Sul: VI Seminário de Pesquisa em Educação da Região Sul. UNIVALI, Itajaí, 2008, p. 1-19.

JACOBI, Pedro Roberto. Educação Ambiental: o desafio da construção de um pensamento crítico, complexo e reflexivo. Educação e Pesquisa, São Paulo, v. 31, n. 2, p. 233-250, maio/ago. 2005.

KUHN, Thomas S. A estrutura das revolucões científicas. 3. ed. São Paulo: Perspectiva, 1990.

LAROCCA, Priscila; ROSSO, Ademir José; SOUZA, Audrey Pietrobelli de. A formulação dos objetivos de pesquisa na pós-graduação em educação: uma discussão necessária. Revista Brasileira de Pós-Graduação, Brasília, v. 2, n. 3, p. 118-133, mar/2005.

LEFF, Enrique. Saber ambiental: sustentabilidade, racionalidade, complexidade e poder. 2. ed. Petrópolis: Vozes, 2002.

- Aventuras da epistemologia ambiental: da articulação das ciências ao diálogo dos saberes. Rio de Janeiro: Garamond, 2004.

LENOIR, Yves. Pesquisar e formar: repensar o lugar e a função da prática de ensino. Educação \& Sociedade, Campinas, v. 27, n. 97, p. 1299-1325, set./dez. 2006. 
LIMA, Gustavo da Costa. O discurso da sustentabilidade e suas implicações para a educação. Ambiente \& Sociedade, Campinas, v. 6, n. 2, p. 99-119, jul./dez. 2003.

LORENZETTI, Leonir; DELIZOICOV, Demetrio. A produção acadêmica do mestrado em educação ambiental da FURG - 1997-2005. In: ENCONTRO DE PESQUISA EM EDUCAÇÃO AMBIENTAL, 4., 2007, Rio Claro. Questões Epistemológicas Contemporâneas: o debate modernidade e pós-modernidade. Rio Claro, 2007. v. 1. p. 1-12.

LUSTOSA, Maria Gabriela Lopes; MATOS, Maria C. de F. G.; LOUREIRO, Carlos Frederico B. O estado da arte da educação ambiental brasileira a partir do V Fórum Brasileiro de Educação Ambiental: agentes sociais e problemáticas. In: ENCONTRO DE PESQUISA EM EDUCAÇÃO AMBIENTAL, 4., 2007, Rio Claro. Questões Epistemológicas Contemporâneas: o debate modernidade e pós-modernidade. Rio Claro, 2007. v. 1. p. 1-12.

MEDEIROS, Mara Glacenir Lemes de; BELLINI, Luzia Marta. Educação ambiental como educaşão científica: desafios para empreender ambientes sob impactos. Londrina: EDUEL, 2001.

MIRANDA, Marilia Gouvea de.; RESENDE, Anita C. Azevedo. Sobre a pesquisaação na educação e as armadilhas do praticismo. Revista Brasileira de Educação, v. 11, n. 33, p. 511-518, set./dez. 2006.

MORAES, Maria Célia M. de. Recuo da teoria: dilemas na pesquisa em educação. ANPED. http://www.anped.org.br/24/T1722216449491.doc, p 1-17.

MORIN, Edgar. Ciência com consciência. Rio de Janeiro: Bertrand Brasil, 1998.

PEDRINI, Alexandre de Gusmão; DE-PAULA, J. C. A Educação Ambiental: críticas e propostas. In: PEDRINI, Alexandre de Gusmão. Educação Ambiental: reflexões e práticas contemporâneas. Petrópolis: Vozes, 1997. p. 88-145.

POOLI, João Paulo. Decifra-me ou te devoro: a excelência do objeto pela construção do argumento. Educação e Realidade, Porto Alegre, v. 23, n. 2, p. 95-108, dez. 1998.

REIGOTA, Marcos Antonio dos Santos. Ciência e Sustentabilidade: a contribuição da educação ambiental. Avaliação, Campinas, v. 12, n. 2, p. 219-232, jun. 2007.

ROSSO, Ademir José. A distância entre a Educação Ambiental projetada e a forma como se efetiva o Ensino de Ciências. In: GUERRA, Antonio Fernando S.; TAGLIEBER, José Ermo (Org.). Educação Ambiental: Fundamentos, Práticas e Desafios. Itajaí, SC: UNIVALI, 2007. p. 125-142.

ROSSO, Ademir José; SILVA, Franciely Ribeiro da; MACHADO, Bernadete. A dimensão investigativa e formativa de um evento de Educação Ambiental. In: $I V$ Encontro de Pesquisa em Educação Ambiental, 2007, Rio Claro. "Questões Epistemológicas Contemporâneas: o debate modernidade e pós-modernidade. Rio Claro, 2007. v. 1. p. 1-12.

SANTOS, Boaventura de Sousa. Introdução a uma ciência pós-moderna. Rio de Janeiro: Graal, 1989. 
- Para uma sociologia das ausências e uma sociologia das emergências. In: - (Org.). Conhecimento prudente para uma vida descente: um discurso sobre as ciências revisitado. São Paulo: Cortez, 2004. p. 777-821.

SATO, Michèle; GAUTHIER, Jacques Zanidê; PARIGIPE, Lymbo. Insurgência do grupo pesquisador na educação sociopoética. In: SATO, Michèle; CARVALHO, Isabel Cristina de Moura. Educação Ambiental: pesquisa e desafio. Porto Alegre: Artmed, 2005. p. 99-117.

SATO, Michèle; SANTOS, José Eduardo dos. Tendências nas pesquisas em educação ambiental. In: NOAL, Fernando Oliveira; BARCELOS, Valdo Hermes de Lima (Org.). Educação ambiental e cidadania: cenários brasileiros. Santa Cruz do Sul: UDUNISC, 2003. p. 253-283.

SAUVÉ, Lucie. Uma cartografia das correntes em educação ambiental. Tradução de Ernani Rosa. In: SATO, Michèle; CARVALHO, Isabel Cristina de Moura (Org.). Educação Ambiental: pesquisa e desafio. Porto Alegre: Artmed, 2005. p. 17-44.

WARDE, Mirian Jorge. O papel da pesquisa na pós-graduação em educação. Cadernos de Pesquisa, São Paulo, n. 73, p. 67-75, maio 1990.

Artigo: recebido em 30/06/2009 - aprovado em 05/11/2009 